\title{
Inflammatory Mediators Sensitize Acutely Axotomized Nerve Fibers to Mechanical Stimulation in the Rat
}

\author{
Martin Michaelis, Carola Vogel, Karl-Heinz Blenk, Adalsteinn Arnarson, and Wilfrid Jänig \\ Physiologisches Institut, Christian-Albrechts-Universität, 24098 Kiel, Germany
}

Many axotomized myelinated as well as unmyelinated cutaneous nerve fibers are sensitive to mechanical stimuli applied to the cut nerve end within a few hours after nerve lesion. Here we investigated the influence of inflammatory mediators on this ectopic mechanosensitivity after cutting and ligating the sural nerve in anesthetized rats. Neural activity was recorded from single axons in filaments teased from the sural or sciatic nerve proximally to the lesion site 2-33 hr after axotomy. Using calibrated von Frey hairs (1.0-128.5 mN), $30 \mathrm{sec}$ trains of phasic stimuli were applied to the cut nerve end immediately before and after local application of a mixture of inflammatory mediators [inflammatory soup (IS), consisting of bradykinin, 5-HT, prostaglandin $\mathrm{E}_{2}$, histamine (all $10 \mu \mathrm{M}$ ), and $\mathrm{K}^{+} 7 \mathrm{~mm}, \mathrm{pH}$ 7.0] for $2 \mathrm{~min}$. Before as well as after IS application, von Frey thresholds were significantly lower in myelinated $(A)$ fibers than in unmyelinated $(C)$ fibers. IS application enhanced the ectopic mechanical excitability, as expressed in reduced von Frey thresholds and increased response magnitudes, of most severed mechanosensitive $\mathrm{C}$ fibers (77\%) and some mechanosensitive A fibers (46\%). The sensitization lasted for 10-40 min after a 2 min IS application. Additionally, among axotomized nerve fibers unresponsive to probing of the nerve lesion site before IS application, 1 of 63 (1.6\%) A and 3 of $106(2.8 \%)$ C fibers became mechanosensitive immediately after IS application. The results indicate that after axotomy, inflammatory processes augment touch-evoked ectopic activity in lesioned sensory nerve fibers. Because many affected afferents are presumably of nociceptive function, their enhanced neural barrage may contribute to neuropathic pain states.

Key words: axotomy; hyperalgesia; inflammation; sensitization; pain; electrophysiology
Axons of many cutaneous afferent neurons, when severed by a peripheral nerve lesion, become hyperexcitable close to the lesion site. Within $30 \mathrm{hr}$, mechanical stimuli of intensities that do not induce action potentials when applied to an intact nerve excite up to $25 \%$ of all myelinated axotomized cutaneous nerve fibers and $\sim 6 \%$ of the unmyelinated fibers (Koschorke et al., 1991; Michaelis et al., 1995). Moreover, 4\% of axotomized unmyelinated (C) fiber afferents were excited by brief applications of a combination of inflammatory mediators [inflammatory soup (IS)], whereas myelinated (A) fibers were not excited (Michaelis et al., 1997b). Mechanical and inflammatory stimuli also excite some axon endings trapped in long-standing neuromata, i.e., days or months after transection of a nerve (Blumberg and Jänig, 1984; Welk et al., 1990; Devor et al., 1992), and in the chronic constriction injury model of neuropathic pain (Clatworthy et al., 1995; Xie et al., 1995; Tal and Eliav, 1996). Whether inflammatory mediators are capable of augmenting substantially the ectopic responsiveness to mechanical stimuli in acutely axotomized afferents is not yet known.

When an inflammation affects the receptive endings of intact spinal afferents, their threshold for activation may decrease and their response magnitude to constant stimuli may increase (Treede et al., 1992; Reeh and Kress, 1995). This sensitization process, which is caused by endogenous mediators such as brady-

Received Jan. 23, 1998; revised June 30, 1998; accepted July 2, 1998.

This work was supported by the Deutsche Forschungsgemeinschaft (Mi 457/2-1, Ja 240/13-3). We thank Elspeth McLachlan for discussion and Eike Tallone for her help with the illustrations.

Correspondence should be addressed to Dr. Martin Michaelis, Physiologisches Institut, Christian-Albrechts-Universität, Olshausenstrasse 40, D-24098 Kiel, Germany.

Copyright (C) 1998 Society for Neuroscience $\quad 0270-6474 / 98 / 187581-07 \$ 05.00 / 0$ kinin, prostaglandins, and others (Levine and Taiwo, 1994), may enhance the mechanosensitivity of afferent neurons, as has been demonstrated recently for trigeminal meningeal afferents (Strassman et al., 1996). Analogous changes are exhibited by deep somatic afferents supplying the knee joint (Schaible and Schmidt, 1988) and some visceral afferents from the urinary bladder (Häbler et al., 1990) in the course of an acute tissue inflammation. In an in vivo experiment on monkeys, half of all nociceptive cutaneous afferents tested were sensitized to mechanical stimuli by IS (Davis et al., 1993), whereas an intensive search for a sensitizing effect of IS on saphenous nerve afferents to mechanical stimulation failed in an in vitro rat skin-nerve preparation (Kessler et al., 1992).

The present study was undertaken to elucidate the influence of inflammatory mediators on ectopic mechanosensitivity of acutely axotomized cutaneous afferents. This was performed with emphasis on both $\mathrm{C}$ fiber afferents with presumably nociceptive function and myelinated afferents with predominantly nonnociceptive function.

Preliminary results have been published previously in abstract form (Michaelis et al., 1997a).

\section{MATERIALS AND METHODS}

Surgical preparation. Male and female Wistar rats $(n=17$; body weight $250-600 \mathrm{gm}$ ) were used for the experiments. Anesthesia was induced by intraperitoneal injection of pentobarbital sodium (Nembutal, $60 \mathrm{mg} / \mathrm{kg}$ ). Tail artery and jugular vein catheters were inserted for continuous blood pressure recording and for regular administration of additional doses of pentobarbital $\left(10-20 \mathrm{mg} \cdot \mathrm{kg}^{-1} \cdot \mathrm{hr}^{-1}\right.$, i.v. $)$, respectively. Anesthesia was kept at a sufficient level as judged from the absence of corneal reflexes, withdrawal reflexes, and spontaneous gross blood pressure fluctuations. Throughout the experiments, mean arterial blood pressure exceeded 60 $\mathrm{mmHg}$. The trachea was cannulated, and the animals breathed sponta- 
neously. Blood gases were measured regularly (ABL30, Radiometer, Copenhagen). If necessary (decrease of $\mathrm{P}_{\mathrm{O}_{2}}$ below $65 \mathrm{mmHg}$ ), some animals were paralyzed with Pancuronium (Organon, Teknika Cappel, Durham, NC) (1 mg/kg, i.v.) and artificially ventilated with a gas mixture of $40 \% \mathrm{O}_{2}$ and $60 \% \mathrm{~N}_{2}$. Rectal temperature was kept close to $37.0^{\circ} \mathrm{C}$ using a servo-controlled heating blanket. At the end of the experiments, the animals were killed by intravenous injection of a saturated potassium chloride solution that was given under deep anesthesia. All experiments had been approved by the local animal care committee of the state administration and were conducted in accordance with German federal law.

On the left side, the sural nerve was exposed and, near the ankle, was tightly ligated (6-0 silk) and cut distal to the ligature. This was performed in six animals under pentobarbital anesthesia on the day before the acute electrophysiological experiment; the incision was closed and recovery was uneventful. In 11 animals, the sural nerve ligation and transection were performed at the beginning of the acute electrophysiological experiment. For nerve recording, either the sural nerve at its junction with the sciatic nerve or the sciatic nerve distally from where it passed under the pelvic ischium was isolated from connective tissue, cut proximally, and placed on a rigidly fixed small black Perspex platform. The nerve from the distal transection site to the recording site together with surrounding tissues was covered with warm $\left(37^{\circ} \mathrm{C}\right)$ paraffin oil in a common pool made from the skin flaps.

Recording and electrical stimulation. A pair of platinum electrodes was positioned at the sural nerve $5-10 \mathrm{~mm}$ proximal to the ligature for electrical stimulation. The proximal end of the sural nerve was split with the aid of fine jeweler forceps for single fiber recording. In five experiments, single fibers projecting in the sural nerve were isolated from the sciatic nerve. Nerve filaments were placed on a platinum wire electrode referred to an indifferent electrode connected to nearby tissue. Spike discrimination was controlled by means of a delay circuit. The sural nerve was electrically stimulated with square wave pulses of $0.1-0.5 \mathrm{msec}$ duration at $0.3 \mathrm{~Hz}$ at variable intensities up to $30 \mathrm{~V}$, and fibers were identified as $\mathrm{A}$ or $\mathrm{C}$ fibers according to their conduction velocity. Some mechanosensitive axotomized fibers that could not be identified during electrical stimulation were classified offline as A or C fibers (7/25 A fibers, $5 / 20 \mathrm{C}$ fibers) according to a combination of five criteria: number of action potential (AP) phases (biphasic or triphasic), width of the first AP phase (in milliseconds), amplitude of the first AP phase divided by the time from onset of the AP until first voltage peak (millivolts per millisecond), maximum amplitude of the AP $\left(V_{\max }\right)$ divided by the duration of the maximum amplitude (millivolts per millisecond), and ratio of $V_{\max }$ and the amplitude of the first AP phase (millivolts per millivolt). In this way, $\sim 93 \%$ of the fibers can be assigned reliably to one of the two groups (Blenk et al., 1996).

Experimental procedure. Axotomized nerve fibers were investigated between 2 and $33 \mathrm{hr}$ after sural nerve ligation and transection. Every filament was first checked to determine whether it contained mechanically excitable fibers by probing the cut nerve end with a blunt glass rod. The conduction velocity of mechanosensitive fibers was determined by electrically stimulating the sural nerve; moreover, by varying the stimulus intensity, the numbers of $\mathrm{A}$ and $\mathrm{C}$ fibers within the filament were determined. Mechanical sensitivity was investigated in more detail using calibrated von Frey hairs with circular plain tips of $0.5 \mathrm{~mm}$ diameter made from nylon filaments (diameter 0.1-0.25 mm, length 15-45 mm). This tip diameter was the same size as the diameter of the cut nerve end. The von Frey hairs exerted forces of 1.0-128.5 mN. Each mechanosensitive fiber was tested with at least three different von Frey hairs with suprathreshold strengths. Within each trial, which lasted $30 \mathrm{sec}$, the von Frey hairs were repeatedly put on the nerve lesion site just proximal to the ligature for durations of $100-200 \mathrm{msec}$ at a repetition rate of 50 stimuli/30 sec using a metronome. The same stimulation paradigm (50 stimuli in $30 \mathrm{sec}$ ) was used to determine the von Frey threshold, defined as the strength of the finest filament that evoked at least 2 impulses/30 sec.

After determination of quantitative responses to mechanical stimuli, the nerve lesion site was exposed to a combination of inflammatory mediators (IS). Small square pieces of filter paper $\left(\sim 4 \mathrm{~mm}^{2}\right)$ soaked in solution of similar temperature as the paraffin oil in the pool were placed on the nerve end, so that the lesion site and the nerve just proximal to it were covered. IS contained histamine, 5-HT, bradykinin, prostaglandin $\mathrm{E}_{2}\left(\mathrm{PGE}_{2}\right)\left(\right.$ all $\left.10^{-5} \mathrm{M}\right)$, and $\mathrm{K}^{+}(7 \mathrm{mM}), \mathrm{pH} 7.0$ (Kessler et al., 1992). Stock solutions $\left(10^{-3} \mathrm{M}\right)$ of all individual drugs used were kept at $-20^{\circ} \mathrm{C}$ and were diluted on the day of the experiment in Tyrode's solution. In the stock solution, $\mathrm{PGE}_{2}$ was dissolved in DMSO (Sigma, St. Louis,
MO). Tyrode's solution, $\mathrm{pH}$ 7.0, with $\mathrm{K}^{+}$and DMSO concentrations as in IS were used as a control solution. The filter paper soaked with IS or control solution was left on the nerve end for $120 \mathrm{sec}$, which was followed by a $30 \mathrm{sec}$ application of Tyrode's solution. Thereafter, aqueous solutions were sucked out of the pool and replaced by additional paraffin oil. Within $5 \mathrm{~min}$ after removing IS, the nerve end was again stimulated mechanically using at first a von Frey hair with a strength either equal to or slightly below its control threshold. When recording from the next filament, IS was administered at least $30 \mathrm{~min}$ after the last IS application.

Data processing. Neural activity and arterial blood pressure were stored on magnetic tape (EMI SE 7000) or a digital tape recorder (DTR-2602, Biological, Claix, France) for further analysis [custom data acquisition software (CARDS by S. Tiedemann, University of Keil, Germany) and template-matching program (Forster and Handwerker, 1990)]. Statistical evaluations are based on ANOVA and paired $t$, Wilcoxon, MannWhitney $U$, and $\chi^{2}$ tests.

\section{RESULTS}

We recorded from 355 axotomized cutaneous nerve fibers before and after a 2 min application of a combination of inflammatory mediators (IS application). Among these, 25/148 myelinated A fibers and 20/207 unmyelinated C fibers responded to local mechanical stimulation of the cut nerve end either before as well as after IS application (24 A fibers, $17 \mathrm{C}$ fibers) or after but not before IS application (one A fiber, three $\mathrm{C}$ fibers). Moreover, eight mechanosensitive A fibers and four mechanosensitive $\mathrm{C}$ fibers of an additional group of 73 axotomized cutaneous nerve fibers (38 A fibers, $35 \mathrm{C}$ fibers) served as controls.

The mechanosensitivity of the lesioned sural nerve was restricted to $1 \mathrm{~mm}$ just proximal to the ligature. When excited here by von Frey hair stimulation, axotomized cutaneous nerve fibers fired a single action potential or a short burst $(<100 \mathrm{msec})$ of action potentials (Fig. 1); tonic firing to sustained mechanical force was never found. Because of the phasic response behavior, we applied the von Frey hairs repeatedly in each stimulation period of $30 \mathrm{sec}$ duration with a repetition rate of $50 \mathrm{stimuli} / 30$ sec. Within bursts, the interspike interval sometimes was below 10 msec (Fig. 1).

The total number of action potentials in response to a standard $30 \mathrm{sec}$ stimulation period increased with the strength of the von Frey filament (Figs. 1, 2). Responses of eight myelinated axotomized nerve fibers with similar thresholds $(2$ or $3 \mathrm{mN})$ were averaged and yielded a significant response increase with increasing filament strength (Fig. 2A, inset). Among mechanically excitable $\mathrm{C}$ fibers, von Frey thresholds were rather dispersed (Fig. $3 A$ ), and therefore no averaged stimulus-response curve was constructed.

The magnitude of response to mechanical stimulation was reliably reproducible (Fig. 2B). With use of the same von Frey hair, stimulus trains were repeated within $<10 \mathrm{~min}$, and the responses to the first stimulus train were not statistically different from the responses to the second (Fig. 2B, Table 1, I).

For 18/24 mechanosensitive axotomized A fibers and 14/17 mechanosensitive axotomized $\mathrm{C}$ fibers, von Frey thresholds were determined before and within 5 min after IS application. Average thresholds were significantly lower in axotomized A fibers than in C fibers before $(2.0 \mathrm{mN}$ vs $8.8 \mathrm{mN}$, median) and after IS application $(1.5 \mathrm{mN}$ vs $4.4 \mathrm{mN}$, median; $p<0.01$, Mann-Whitney $U$ test). The threshold of $6 \mathrm{~A}$ fibers was below $2 \mathrm{mN}$ before as well as after IS application; the other A fibers and all $\mathrm{C}$ fibers exhibited thresholds of $\geq 2 \mathrm{mN}$ before IS application. Among the latter, thresholds declined significantly after IS application compared with pre-IS values in the population of $\mathrm{C}$ fibers but not in the population of A fibers (Fig. $3 A$ ).

We also tested the effect of IS on the magnitude of responses 

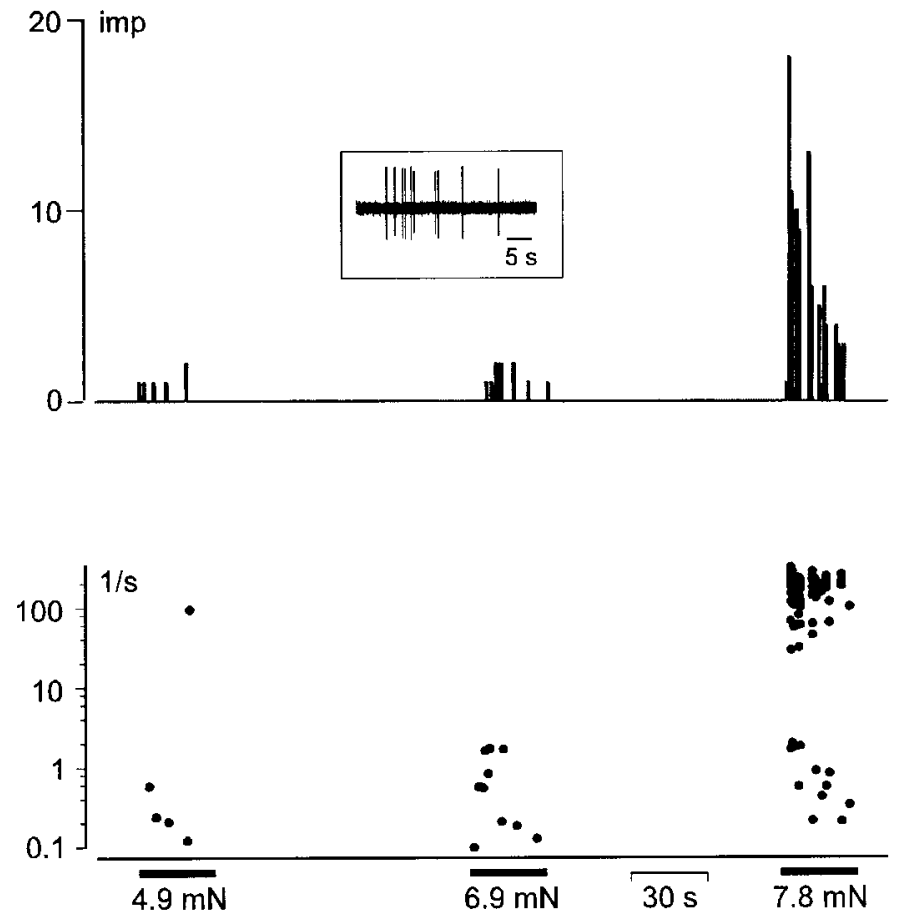

Figure 1. Typical phasic responses of a single axotomized myelinated nerve fiber (conduction velocity $50 \mathrm{~m} / \mathrm{sec}$ ) to local mechanical stimulation of the cut nerve end with von Frey filaments of different strength $5 \mathrm{hr}$ after nerve lesion. Duration of each trial was $30 \mathrm{sec}$ (marked by bars); repetition rate of mechanical stimuli within the trials was 50 stimuli/30 sec. Responses are shown as time-activity histogram (top panel; bin width $1 \mathrm{sec}$ ) and as time-frequency histogram, where each dot represents one action potential (bottom panel). Inset shows mechanically evoked action potentials.

using von Frey hairs of the same strength before and immediately after IS application. The response magnitude increased significantly among $\mathrm{C}$ fibers but did not change among A fibers (Fig. $3 B$ ). Combining $\mathrm{A}$ and $\mathrm{C}$ fiber response magnitudes, the observed increase induced by IS was significant (Table 1, III). In additional experiments, application of a control solution containing $\mathrm{K}^{+}$and DMSO in concentrations equal to those of IS did not produce a significant increase in response magnitude in $\mathrm{A}$ and $\mathrm{C}$ fibers (Table 1, II). Moreover, when IS was applied subsequently to control solution, responses to von Frey stimuli were unchanged after control solution but significantly enhanced after IS (Table 1, IV).

An axotomized nerve fiber was thought to be sensitized to mechanical stimuli if the von Frey threshold dropped by $\geq 50 \%$ and/or the response magnitude increased by more than or equal to four times compared with pre-IS values. Using these criteria, 11/24 A fibers and 13/17 C fibers were sensitized by IS. Additionally, axotomized nerve fibers that did not respond to glass rod stimulation of the cut nerve end before IS application were studied for possible development of mechanosensitivity after IS application. Within 5 min of IS application, 1/62 A fibers (1.6\%) and $3 / 106 \mathrm{C}$ fibers $(2.8 \%)$ became mechanosensitive. Such recruited nerve fibers will also be called sensitized.

IS directly excited 1/148 (0.7\%) A fibers and 6/207 (2.9\%) C fibers. Among these, three $\mathrm{C}$ fibers were mechanosensitive before IS application; all three were sensitized by IS. The A fiber exhibited mechanosensitivity for the first time after IS application. The remaining three $\mathrm{C}$ fibers were unresponsive to mechan-
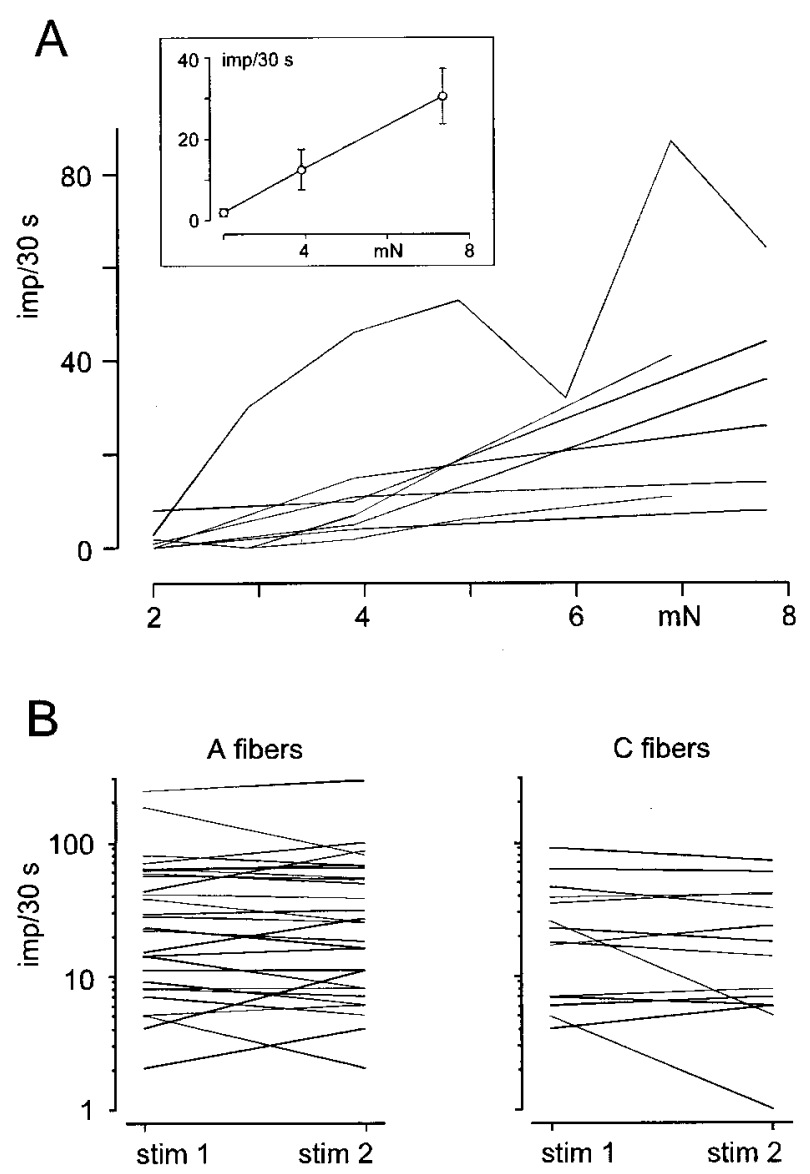

Figure 2. A, Stimulus-response curves obtained from eight axotomized myelinated nerve fibers with von Frey threshold of $2-3 \mathrm{mN}$. Data show the total number of action potentials evoked during stimulation periods of 30 sec duration $(\mathrm{imp} / 30 \mathrm{~s})$. Inset exhibits the averaged responses $( \pm \mathrm{SEM})$, which increased significantly with stimulus strength $(p<0.005$, ANOVA). B, Quantitative responses (impulses/30 sec) induced by two consecutive stimulus trains (stim 1, stim 2; interval between stimulus trains $<10 \mathrm{~min}$ ) with the same von Frey filament, of $19 \mathrm{~A}$ fibers and $10 \mathrm{C}$ fibers (Table 1, I). Some fibers (9/19 A, 4/10 C) were tested twice with two consecutive stimulus trains using two different stimulus strengths. Repetition rate of mechanical stimuli within the trials was 50 stimuli $/ 30 \mathrm{sec}$.

ical stimuli applied to the nerve lesion site before and after IS. Moreover, spontaneous activity was observed in 8/207 (3.9\%) C fibers but not in A fibers. IS evoked a slight increase in mean spontaneous discharge rate from $0.5 \pm 0.7 \mathrm{~Hz}( \pm \mathrm{SD})$ to $0.8 \pm 1.4$ $\mathrm{Hz}$, which did not reach statistical significance $(p>0.3$, paired $t$ test).

Two confounding methodological factors might have influenced the prevalence of sensitization of axotomized nerve fibers by IS as reported in the present study. First, during each experiment, often more than one nerve filament was tested for ISinduced sensitization, with the consequence that IS had already been applied to the cut nerve end before the onset of investigation of many nerve fibers. Second, the time between the nerve lesion and testing for IS-induced sensitization varied between 2 and 33 hr. The number of preceding IS applications was found not to significantly change the prevalence of sensitized nerve fibers: 6/11 A fibers and 7/9 C fibers were sensitized when no application or one IS application preceded the test. When there were three or more preceding IS applications, 2/9 A fibers and 6/7 C fibers were 
A

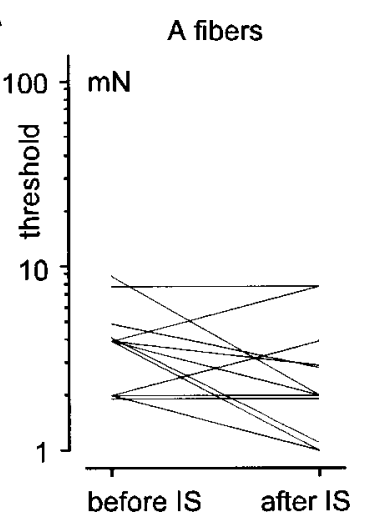

B

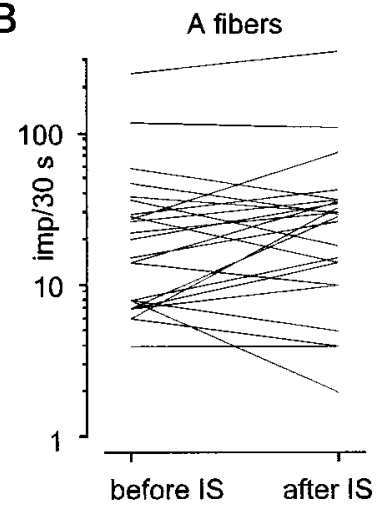

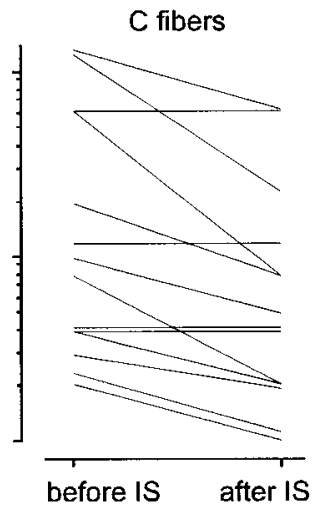

C fibers

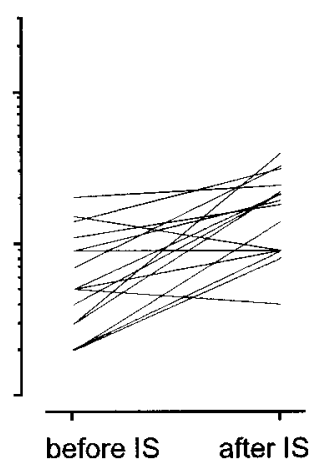

Figure 3. Ectopic mechanosensitivity of axotomized A and C fibers before and within $5 \mathrm{~min}$ of local application of inflammatory soup (IS) to the cut nerve end. $A$, IS induced a significant decrease of von Frey threshold in C fibers $(n=14$; median $8.8 \mathrm{mN}$ vs $4.4 \mathrm{mN}$; range $2-128.5 \mathrm{mN}$ vs $1-61.8 \mathrm{mN})$ but not in A fibers $(n=12$; median $3.9 \mathrm{mN}$ vs $2.0 \mathrm{mN}$; range $2-8.8 \mathrm{mN}$ vs $1-7.8 \mathrm{mN} ; p<0.01$ and $p>0.19$, respectively; Wilcoxon matched-pairs test). $B$, Response magnitude obtained from 24/25 A and 16/20 C fibers with ectopic mechanosensitivity; stimulation with the same von Frey intensity before and after IS application (repetition rate of mechanical stimuli within the trials, $50 \mathrm{stimuli} / 30 \mathrm{sec}$ ) yielded a significant increase in $\mathrm{C}$ but not in A fibers $(p<0.005$ and $p>0.15$, respectively; Wilcoxon matched-pairs test). Duration of IS applications was $2 \mathrm{~min}$. For one sensitized $\mathrm{C}$ fiber showing a clear decrease in threshold after IS application, no response magnitude induced by stimulation with the same von Frey hair before and after IS was measured.

sensitized ( $p>0.14$ and $p>0.68, \chi^{2}$ test) (Fig. 4). Also the time after the nerve lesion had no significant influence on the prevalence: 7/14 A (12/16 C) fibers were sensitized 2-17.5 hr after nerve lesion, and 5/11 A (4/4 C) fibers were sensitized after 17.5-33 hr ( $p>0.82$ and $p>0.26, \chi^{2}$ test) (Fig. 4$)$.

We investigated the duration and reproducibility of IS-induced sensitizations. The cut nerve end was stimulated with stimulus intensities immediately below threshold (three A fibers, three C fibers) or at threshold strength (one A fiber) before IS application. After IS application, each fiber was stimulated with the same von Frey hair, and the mechanical excitability increased distinctly (Fig. 5). However, a second or third stimulus repetition evoked reduced numbers of action potentials, and in all fibers the pre-IS levels of mechanical excitability were largely reached within 40 min. A second IS application to the lesion site a short time after return of the response magnitudes to pre-IS values again increased mechanical excitability in the same fibers (Fig. 5).

\section{DISCUSSION}

Many axotomized cutaneous afferents are sensitive to mechanical stimulation of the lesion site within a few hours of a peripheral nerve transection. We demonstrate that inflammatory mediators are capable of further increasing this ectopic mechanosensitivity. However, not all afferents are likewise affected, because a sensitization was found in most axotomized mechanosensitive $\mathrm{C}$ fibers, yet was found less often among mechanosensitive A fibers. We suggest that a sensitizing effect of inflammatory mediators is restricted to particular functional classes of primary afferent neurons, e.g., unmyelinated and myelinated nociceptive afferents.

We have concentrated on axotomized fibers that exhibited mechanical excitability when stimulated by probing the nerve lesion site. These fibers were most likely afferent, although $20 \%$ of all A fibers (Peyronnard et al., 1986) and $15 \%$ of all $\mathrm{C}$ fibers in the rat sural nerve (Baron et al., 1988) are efferent motor or sympathetic fibers, respectively. Recording from both $\mathrm{L}_{5}$ ventral and dorsal roots $7 \mathrm{~d}$ after ligating the common peroneal nerve, none of 63 identified ventral root A fibers responded to mechanical stimulation of the nerve injury site, in marked contrast to 14/30 (47\%) myelinated dorsal root fibers (Koschorke et al., 1991). Furthermore, intact sympathetic fibers are unresponsive to mechanical stimuli at intensities known to excite $\mathrm{C}$ fiber cutaneous afferents, as shown in a study using microneurography (Schmidt et al., 1994). Therefore, it is reasonable to assume that axotomized sympathetic efferents remain unresponsive to mechanical stimuli too.

In the present investigation we have used a combination of several mediators to mimic the pathophysiological situation of tissue inflammation. There are numerous indications that inflammatory mediators are capable of exciting and sensitizing intact afferent nerve fibers via specific membrane receptors and connected intracellular signal cascades. Thus, $\mathrm{PGE}_{2}$ sensitized cutaneous $\mathrm{C}$ fiber afferents to von Frey hair stimulation (Martin et al., 1987). As has been concluded from behavioral and electrophysiological experiments (Khasar et al., 1995; Wang et al., 1996), this sensitization is presumably mediated by multiple prostaglandin E receptor subtypes via the cAMP second messenger system. BK induced a transient excitation in some intact cutaneous nociceptors (Lang et al., 1990; Dray and Perkins, 1993) and a sustained sensitization to heat in even more nociceptors (Haake et al., 1996). Both effects were mediated by BK receptors type 2 but probably by different intracellular pathways (Reeh and Sauer, 1997). Serotonin likewise contributes as a mediator to primary afferent sensitization, reacting with specific membrane receptors (Beck and Handwerker, 1974; Taiwo and Levine, 1992).

The subcellular mechanisms leading to IS-induced sensitization of axotomized afferents for mechanical stimulation are unknown. Within $30 \mathrm{hr}$ after nerve transection, mechanically evoked excitation of cut axons is very likely mediated by transducer mechanisms that are specific for these axons, because almost all mechanosensitive axotomized fibers are not thermosensitive, and most thermosensitive axotomized fibers were not excited by mechanical stimuli (Michaelis et al., 1995; Blenk et al., 1996; Michaelis et al., 1998). This hypothesis is supported by others who have recorded from functionally characterized classes of primary afferents in cats (Johnson and Munson, 1991) and electric fish (Devor et al., 1990), showing that a few days after axotomy these afferents exhibited physiological properties similar to intact afferents of the same functional class. The transducer mechanisms are probably based on specific proteins that are synthesized in the 
Table 1. Magnitude of responses to mechanical stimulation of the lesion site in axotomized cutaneous nerve fibers

Impulses/30 sec evoked by consecutive trains of von Frey hair stimuli

\begin{tabular}{|c|c|c|c|c|c|c|c|}
\hline & Fibers $n(\mathrm{~A}, \mathrm{C})$ & Tests $n(\mathrm{~A}, \mathrm{C})$ & $\begin{array}{l}\text { (1) Stimulus train } \\
\text { median; range }\end{array}$ & Treatment & $\begin{array}{l}\text { (2) Stimulus train } \\
\text { median; range }\end{array}$ & Treatment & $\begin{array}{l}\text { (3) Stimulus train } \\
\text { median; range }\end{array}$ \\
\hline I & $29(19,10)$ & $42(28,14)$ & $23.0 ; 2-244$ & & $21.0 ; 1-295^{*}$ & & \\
\hline II & $8(5,3)$ & $13(8,5)$ & $40.0 ; 6-98$ & Contr. sol. & $35.0 ; 2-113^{*}$ & & \\
\hline III & $40(24,16)$ & $40(24,16)$ & $9.0 ; 2-244$ & IS & $21.0 ; 2-337^{* *}$ & & \\
\hline IV & $5(2,3)$ & $10(4,6)$ & $29.0 ; 0-68$ & Contr. sol. & $21.5 ; 0-64^{*}$ & IS & $48.0 ; 4-98 * *$ \\
\hline
\end{tabular}

Consecutive trains of von Frey stimuli were applied within 10 min. Treatment between two trains: I, none; II, 2 min application of control solution (Contr. sol.); III, 2 min application of inflammatory soup (IS); IV, application of control solution between (1) and (2) stimulus train followed by IS application between (2) and (3) stimulus train. Some A and C fibers were tested twice with two consecutive trains using two different von Frey hairs. 11/19 A and 6/10 C fibers listed under I were additionally exposed to IS. These fibers and the corresponding responses are therefore also included in III. The remaining eight A and four C fibers of I were either exclusively mechanically stimulated without any treatment between two stimulus trains $(3 \mathrm{~A}, 1 \mathrm{C})$ or additionally received control solution between two trains $(5 \mathrm{~A}, 3 \mathrm{C})$. The responses of the latter fibers induced before and after application of control solution are given under II. A subgroup $(2 / 5 \mathrm{~A}, 3 / 3 \mathrm{C})$ of the latter were tested further by IS; results are given under IV. Wilcoxon matched-pairs test; ${ }^{*} p>0.15 ; * *<<0.005$.
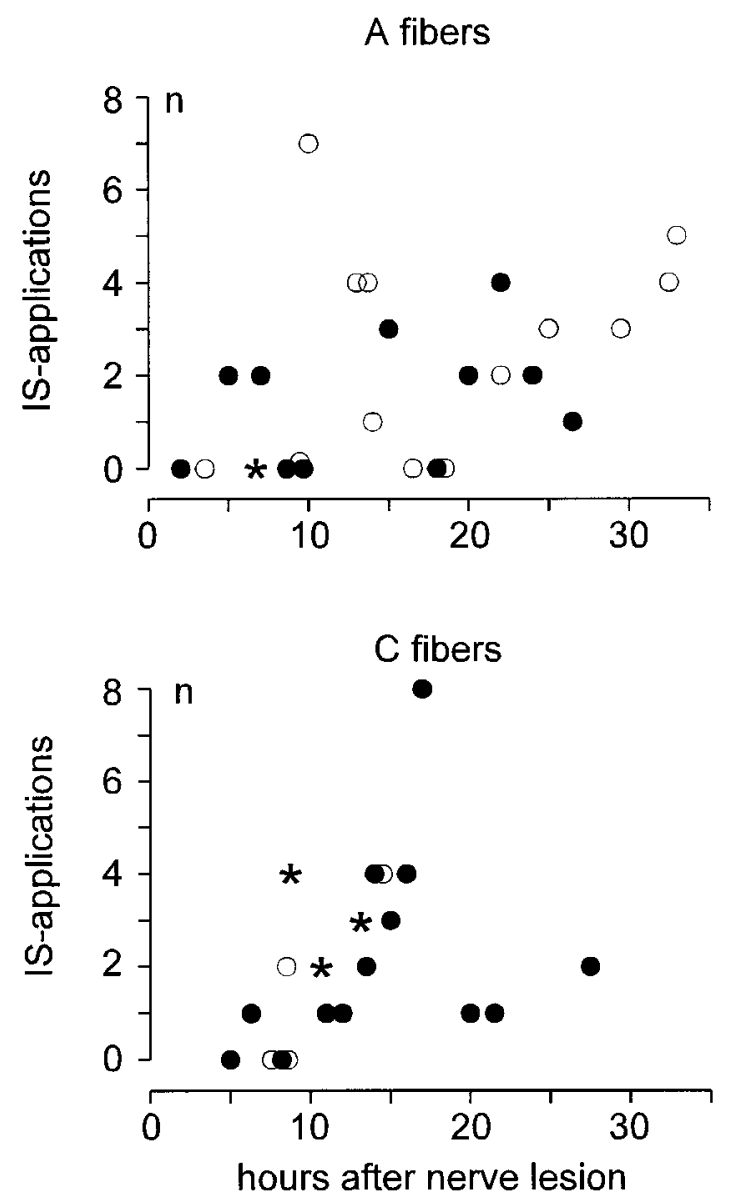

Figure 4. Relationship between time after nerve lesion and number of preceding applications of inflammatory soup $(I S)$ for mechanically excitable axotomized A $(n=25)$ and $\mathrm{C}(n=20)$ fibers. Mechanosensitive fibers that were sensitized/not sensitized by IS application are marked by - or $\bigcirc$, respectively. Initially unresponsive fibers that developed mechanosensitivity after IS are marked by $\star$.

somata of DRG cells, being continuously transported to the lesion site via fast axonal transport, accumulating at and near the lesion site, and probably functionally incorporated into the axon membrane (Devor et al., 1983; Devor, 1994; Koschorke et al., 1994). The same may apply to membrane receptor proteins mediating the sensitization to mechanical stimulation via intracellular pathways.

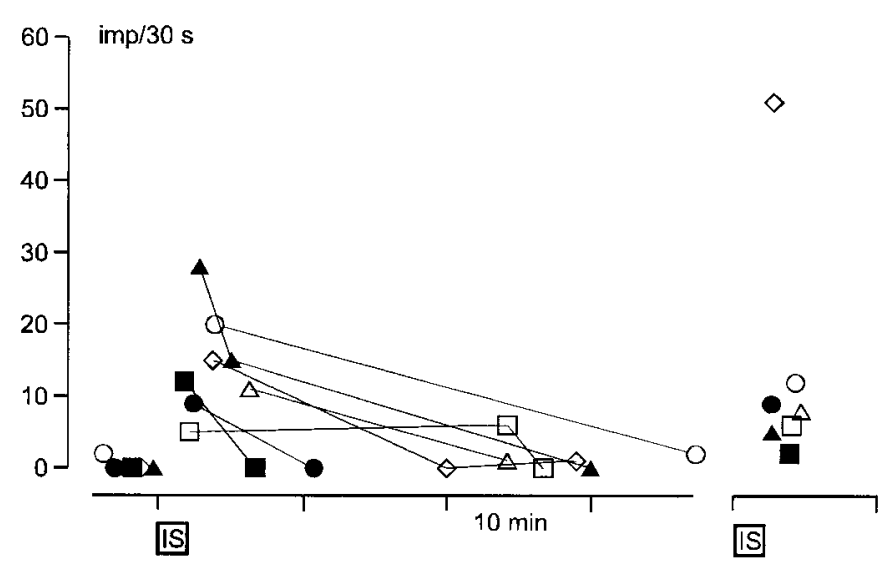

Figure 5. Repetitive sensitization of axotomized nerve fibers induced by two consecutive applications of inflammatory soup $(I S)$. Shown is the number of action potentials evoked by standard von Frey stimulation trials (50 stimuli $/ 30$ sec) in four $\mathrm{A}(\bigcirc, \square, \triangle, \diamond)$ and three $\mathrm{C}(\boldsymbol{\bullet}, \mathbf{\square}, \mathbf{\Delta})$ fibers, each of them tested repeatedly using always the same von Frey hair. The first IS application sensitized all fibers; this effect vanished within $40 \mathrm{~min}$ but was partly reproducible by a second IS application. Duration of IS applications was $2 \mathrm{~min}$.

We speculate that a possible mechanism of increased neuronal excitability underlying sensitization is alteration of sodium currents. In isolated DRG neurons that were not axotomized before dissociation, different inflammatory mediators such as $\mathrm{PGE}_{2}$ and serotonin increased the magnitude and decreased the activation threshold of a tetrodotoxin-resistant (TTX-R) voltage-gated $\mathrm{Na}^{+}$ current that was selectively expressed in a subpopulation of presumed nociceptive neurons (Gold et al., 1996). These alterations are expected to increase excitability substantially. Axotomy likewise changed sodium currents in affected sensory neurons: small axotomized DRG neurons, which were cultured 2-60 d after sciatic nerve ligation, expressed a novel tetrodotoxin-sensitive (TTX-S) $\mathrm{Na}^{+}$current that recovers much faster from inactivation than the TTX-S Na ${ }^{+}$current in control neurons (Cummins and Waxman, 1997). Provided that these changes in sodium currents are not restricted to the cell body membrane, axotomy may enhance excitability of axon endings proximal to the lesion site by expression of a novel TTX-S $\mathrm{Na}^{+}$current, and an additional inflammation may further augment excitability by increasing the remaining TTX-R $\mathrm{Na}^{+}$current. Such an increased excitability would result in lowered thresholds to mechanical and other stimuli and may contribute to the observed sensitization of axotomized afferents. 
Besides inflammatory mediators, other endogenous compounds produce sensitization. As has been shown recently, tumor necrosis factor $\alpha(\mathrm{TNF} \alpha)$, a pro-inflammatory cytokine, induced ongoing activity when applied to an intact peripheral nerve and led to decreased mechanical thresholds in nociceptive afferents when applied near their receptive endings (Sorkin et al., 1997). TNF $\alpha$ was expressed by Schwann cells after a nerve compression lesion (Wagner and Myers, 1996). Moreover, an inflammatory lesion further elevated tissue levels of TNF $\alpha$ (Woolf et al., 1997). Therefore, TNF $\alpha$ may contribute to the sensitizing effect of IS shown in the present study.

Similar to the present results on axotomized afferents, inflammatory mediators have been shown to sensitize about half of the intact nociceptive cutaneous afferents to mechanical stimuli in vivo (Davis et al., 1993). This is in marked contrast to a completely missing sensitizing effect of IS on cutaneous afferents for mechanical stimuli in an in vitro preparation (Kessler et al., 1992). This could mean that IS-induced sensitization is based on nonneuronal cells and/or cell products that are not present in the reduced in vitro preparation, at least not in the necessary concentration.

IS not only increased the sensitivity in mechanosensitive axotomized afferents but it induced mechanosensitivity in some afferents. Intact "silent" afferents that are unresponsive to natural stimuli but are sensitized during an experimentally induced inflammation have been described in several tissues (Schmidt et al., 1994; Michaelis et al., 1996). Mechanically evoked activity in such sensitized normally unresponsive afferents may further increase the neural barrage that reaches the CNS after a nerve lesion.

In our experimental approach, the original sensory function of the afferents before axotomy was not known. Previous studies have shown that acutely axotomized afferents expressed rather selective mechano-, thermo-, or chemosensitivity at the lesion site (Koschorke et al., 1991; Michaelis et al., 1995; Blenk et al., 1996; Michaelis et al., 1997b, 1998). The distribution of these response properties over $\mathrm{A}$ and $\mathrm{C}$ fibers is rather similar for intact and axotomized cutaneous afferents (Michaelis et al., 1998): most thermosensitive intact afferents (Leem et al., 1993) and all thermosensitive axotomized afferents (Blenk et al., 1996) are unmyelinated. Axotomized A fibers had significantly lower von Frey thresholds than $\mathrm{C}$ fiber afferents; a similar difference has been described for intact cutaneous afferents (Leem et al., 1993). Furthermore, we could show that inflammatory mediators significantly sensitized axotomized $\mathrm{C}$ fibers to mechanical stimulation; among intact cutaneous afferents, the capacity to sensitize is particularly a feature of nociceptive afferents (Treede et al., 1992). Therefore we hypothesize that responses in axotomized afferent fibers to stimuli applied to the lesion site preferentially resemble the responses to the same stimuli applied to their receptive endings before nerve lesion.

Consequently, we assume that among the mechanosensitive axotomized $\mathrm{C}$ fibers that showed significant sensitization, many were nociceptive. Thus, tissue inflammation around a nerve lesion site may enhance neuropathic pain according to enhanced touch-evoked barrages in lesioned nociceptive afferents. Because the sensitizing effect is probably mediated by specific membrane receptors, their modulation will open new avenues of neuropathic pain therapies.

\section{REFERENCES}

Baron R, Jänig W, Kollmann W (1988) Sympathetic and afferent somata projecting in hindlimb nerves and the anatomical organization of the lumbar sympathetic nervous system of the rat. J Comp Neurol 275:460-468.

Beck PW, Handwerker HO (1974) Bradykinin and serotonin effects on various types of cutaneous nerve fibers. Pflügers Arch 347:209-222.

Blenk K-H, Michaelis M, Vogel C, Jänig W (1996) Thermosensitivity of acutely axotomized sensory nerve fibers. J Neurophysiol 76:743-752.

Blumberg H, Jänig W (1984) Discharge pattern of afferent fibers from a neuroma. Pain 20:335-353.

Clatworthy AL, Illich PA, Castro GA, Walters ET (1995) Role of periaxonal inflammation in the development of thermal hyperalgesia and guarding behavior in a rat model of neuropathic pain. Neurosci Lett 184:5-8.

Cummins TR, Waxman SG (1997) Downregulation of tetrodotoxinresistant sodium currents and upregulation of a rapidly repriming tetrodotoxin-sensitive sodium current in small spinal sensory neurons after nerve injury. J Neurosci 17:3503-3514.

Davis KD, Meyer RA, Campbell JN (1993) Chemosensitivity and sensitization of nociceptive afferents that innervate the hairy skin of monkey. J Neurophysiol 69:1071-1081.

Devor M (1994) The pathophysiology of damaged peripheral nerves. In: Textbook of pain, Vol 3 (Wall PD, Melzack R, eds), pp 79-100. Edinburgh: Churchill Livingstone.

Devor M, Govrin-Lippmann R (1983) Axoplasmic transport block reduces ectopic impulse generation in injured peripheral nerves. Pain 16:73-85.

Devor M, Keller CH, Ellisman MH (1990) Spontaneous discharge of afferents in a neuroma reflects original receptor tuning. Brain Res 517:245-250.

Devor M, White DM, Goetzl EJ, Levine JD (1992) Eicosanoids, but not tachykinins, excite $\mathrm{C}$-fiber endings in rat sciatic nerve-end neuromas. NeuroReport 3:21-24.

Dray A, Perkins, M (1993) Bradykinin and inflammatory pain. Trends Neurosci 16:99-104.

Forster C, Handwerker HO (1990) Automatic classification and analysis of microneurographic spike data using a PC/AT. J Neurosci Methods 31:109-118.

Gold MS, Reichling DB, Shuster MJ, Levine JD (1996) Hyperalgesic agents increase a tetrodotoxin-resistant $\mathrm{Na}^{+}$current in nociceptors. Proc Natl Acad Sci USA 93:1108-1112.

Haake B, Liang Y-F, Reeh PW (1996) Bradykinin effects and receptor subtypes in rat cutaneous nociceptors, in vitro. Pflügers Arch [Suppl] 431:O26.

Häbler H-J, Jänig W, Koltzenburg M (1990) Activation of unmyelinated afferent fibres by mechanical stimuli and inflammation of the urinary bladder in the cat. J Physiol (Lond) 425:545-562.

Johnson RD, Munson JB (1991) Regenerating sprouts of axotomized cat muscle afferents express characteristic firing patterns to mechanical stimulation. J Neurophysiol 66:2155-2158.

Kessler W, Kirchhoff C, Reeh PW, Handwerker HO (1992) Excitation of cutaneous afferent nerve endings in vitro by a combination of inflammatory mediators and conditioning effect of substance P. Exp Brain Res 91:467-476.

Khasar SG, Ouseph AK, Chou B, Ho T, Green P, Levine JD (1995) Is there more than one prostaglandin $\mathrm{E}$ receptor subtype mediating hyperalgesia in the rat hindpaw? Neuroscience 64:1161-1165.

Koschorke GM, Meyer RA, Tillman DB, Campbell JN (1991) Ectopic excitability of injured nerves in monkey: entrained responses to vibratory stimuli. J Neurophysiol 65:693-701.

Koschorke GM, Meyer RA, Campbell JN (1994) Cellular components necessary for mechanoelectrical transduction are conveyed to primary afferent terminals by fast axonal transport. Brain Res 641:99-104.

Lang E, Novak A, Reeh PW, Handwerker HO (1990) Chemosensitivity of fine afferents from rat skin in vitro. J Neurophysiol 63:887-901.

Leem JW, Willis WD, Chung JM (1993) Cutaneous sensory receptors in the rat foot. J Neurophysiol 69:1684-1699.

Levine JD, Taiwo Y (1994) Inflammatory pain. In: Textbook of pain, Vol 3 (Wall PD, Melzack R, eds), pp 45-56. Edinburgh: Churchill Livingstone.

Martin HA, Basbaum AI, Kwiat GC, Goetzl EJ, Levine JD (1987) Leukotriene and prostaglandin sensitization of cutaneous highthreshold $\mathrm{C}$ - and A-delta mechanonociceptors in the hairy skin of rat hindlimbs. Neuroscience 22:651-659.

Michaelis M, Blenk K-H, Jänig W, Vogel C (1995) Development of spontaneous activity and mechanosensitivity in axotomized afferent 
nerve fibers during the first hours after nerve transection in rats. J Neurophysiol 74:1020-1027.

Michaelis M, Häbler H-J, Jänig W (1996) Silent afferents: a separate class of primary afferents? Clin Exp Pharmacol Physiol 23:99-105.

Michaelis M, Blenk K-H, Vogel C, Arnarson A, Jänig W (1997a) Sensitization of axotomized cutaneous nerve fibers in rats. Soc Neurosci Abstr 23:1954.

Michaelis M, Vogel C, Blenk K-H, Jänig W (1997b) Algesics excite axotomized afferent nerve fibres within the first hours following nerve transection in rats. Pain 72:347-354

Michaelis M, Blenk K-H, Vogel C, Jänig W (1998) Distinct response types are specifically distributed among axotomized cutaneous afferents. Pflügers Arch [Suppl] 435:R154.

Peyronnard JM, Carron L, Lavoie J, Messier JP (1986) Differences in horseradish peroxidase labeling of sensory, motor and sympathetic neurons following chronic axotomy of the rat sural nerve. Brain Res 364:137-150.

Reeh PW, Kress M (1995) Effects of classical algogens. Semin Neurosci 7:221-227.

Reeh PW, Sauer, SK (1997) Chronic aspects in peripheral nociception. In: Proceedings of the 8th World Congress on Pain (Jensen TS, Turner JA, Wiesenfeld-Hallin Z, eds), pp 115-131. Seattle: IASP.

Schaible HG, Schmidt RF (1988) Time course of mechanosensitivity changes in articular afferents during a developing experimental arthritis. J Neurophysiol 60:2180-2195.

Schmidt R, Schmelz M, Forster C, Ringkamp M, Torebjörk HE, Handwerker HO (1994) Novel classes of responsive and unresponsive C nociceptors in human skin. J Neurosci 15:333-343.

Schmidt RF, Schaible H-G, Meßlinger K, Heppelmann B, Hanesch U, Pawlak, M (1994) Silent and active nociceptors: structure, functions and clinical implications. In: Proceedings of the 7th World Congress on
Pain (Gebhart GF, Hammond DL, Jensen TS, eds), pp 213-250. Seattle: IASP.

Sorkin LS, Xiao WH, Wagner R, Myers RR (1997) Tumour necrosis factor-alpha induces ectopic activity in nociceptive primary afferent fibres. Neuroscience 81:255-262 .

Strassman AM, Raymond SA, Burstein R (1996) Sensitization of meningeal sensory neurons and the origin of headache. Nature 384:560-564.

Taiwo YO, Levine JD (1992) Serotonin is a directly acting hyperalgesic agent in the rat. Neuroscience 48:485-490.

Tal M, Eliav E (1996) Abnormal discharge originates at the site of nerve injury in experimental constriction neuropathy $(\mathrm{CCI})$ in the rat. Pain 64:511-518.

Treede R-D, Meyer RA, Raja SN, Campbell JN (1992) Peripheral and central mechanisms of cutaneous hyperalgesia. Prog Neurobiol 38:397-421.

Wagner R, Myers RR (1996) Schwann cells produce tumor necrosis factor alpha: expression in injured and non-injured nerves. Neuroscience 73:625-629.

Wang J-F, Khasar SG, Ahlgren SC, Levine JD (1996) Sensitization of $\mathrm{C}$-fibres by prostaglandin E2 in the rat is inhibited by guanosine $5^{\prime}$-O-(2-thiodiphosphate), 2',5'-dideoxyadenosine and Walsh inhibitor peptide. Neuroscience 71:259-263.

Welk E, Leah JD, Zimmermann M (1990) Characteristics of A- and $\mathrm{C}$-fibers ending in a sensory nerve neuroma in the rat. J Neurophysiol 63:759-766.

Woolf CJ, Allchorne A, Safieh-Garabedian B, Poole S (1997) Cytokines, nerve growth factor and inflammatory hyperalgesia: the contribution of tumour necrosis factor alpha. Br J Pharmacol 121:417-424.

Xie Y, Zhang J, Petersen M, LaMotte RH (1995) Functional changes in dorsal root ganglion cells after chronic nerve constriction in the rat. J Neurophysiol 73:1811-1820. 